\title{
Agricultura familiar como geração de renda e desenvolvimento local: uma análise para Dourados, MS, Brasil*
}

Family Farming as income generation and local development: an analysis in Dourados, MS, Brazil

\section{L'agriculture familiale comme la génération de revenus e développement local: une analyse à Dourados, MS, Brésil}

\author{
Agricultura familiar como la generación de renta y desarrollo local: un análisis para \\ Dourados, MS, Brasil \\ Gleicy Jardi Bezerra** \\ Madalena Maria Schlindwein ${ }^{* * *}$
}

Recebido em 29/02/2016; revisado e aprovado em 24/08/2016; aceito em 06/10/2016

DOI: http:/ / dx.doi.org/10.20435/1984-042X-2016-v.18-n.1(01)

\begin{abstract}
Resumo: Objetivou-se analisar as principais estratégias utilizadas pelos agricultores familiares tradicionais de Dourados, MS, Brasil, para a geração de renda. A metodologia caracteriza-se como pesquisa de campo, a partir de um questionário semiestruturado para uma amostra de 182 agricultores. Conclui-se que a renda obtida fora da propriedade é um importante complemento à renda das famílias. Além disso, é necessário enxergar, na agricultura familiar, o seu potencial de inserção produtiva e seu papel no desenvolvimento local.
\end{abstract}

Palavras-chave: propriedade rural; produtividade; desenvolvimento local.

Abstract: This study aimed to analyze the main strategies used by traditional family farmers in Dourados, MS, Brazil, to increase their income. Its methodology is characterized as field research, with a semi-structured questionnaire for a sample of 182 farmers. In conclusion, the income obtained by farmers outside of their property is an important complement to the family's regular income. Moreover, family farming must be seen in its full potential, as a source of productive inclusion and local development.

Key words: rural property; productivity; local development.

Résumé: Cette étude visait à analyser les principales stratégies utilisées par les agriculteurs traditionnels de Dourados, MS, pour générer des revenus. La méthodologie se caractérise par la recherche sur le terrain , à partir d'un questionnaire semi-structuré pour um échantillon de 182 agriculteurs. En conclusion, le revenu obtenu à l'extérieur de la propriété est un complément important au revenu de la famille. En outre, il est nécessaire de voir dans l'agriculture familiale leur potentiel pour l'inclusion productive et leur rôle dans le développement local.

Mots-clés: propriété rurale; productivité; développement local.

Resumen: Este estudio tuvo como objetivo analizar las principales estrategias utilizadas por los agricultores tradicionales en Dourados, MS, Brasil, para generar ingresos. La metodología se caracteriza por ser una investigación de campo, a partir de un cuestionario semi-estructurado para una muestra de 182 agricultores. En conclusión, los ingresos obtenidos fuera de la propiedad es un complemento importante a los ingresos familiares. Por otra parte, es necesario ver en la agricultura familiar su potencial de inclusión productiva y su papel en el desarrollo local.

Palabras clave: propiedad rural; productividad; desarrollo local.

\footnotetext{
* Este artigo é parte dos resultados da dissertação de mestrado da primeira autora.

** Universidade Federal do Rio Grande do Sul (UFRGS), Porto Alegre, Rio Grande do Sul, Brasil.

*** Universidade Federal da Grande Dourados (UFGD), Dourados, Mato Grosso do Sul, Brasil.
} 


\section{INTRODUÇÃO}

O debate sobre a importância e o papel da agricultura familiar no desenvolvimento brasileiro vem ganhando força ao longo do tempo, impulsionado, principalmente, pela concepção de desenvolvimento duradouro, geração de emprego e renda, segurança alimentar e desenvolvimento local (FAO/INCRA, 2000).

De acordo com a Lei Federal n. 11.326, de 24 de julho de 2006, no artigo $3^{\circ}$ (BRASIL, 2006), são destacadas como características primordiais para se enquadrar como agricultores familiares: (i) não possuir área maior do que quatro módulos fiscais; (ii) a mão de obra utilizada nas atividades econômicas ser predominantemente familiar e (iii) o maior percentual da renda ser obtido das atividades econômicas do estabelecimento. Como agricultura familiar tradicional entendem-se, neste estudo, os agricultores enquadrados na Lei Federal 11.326, de 24 de julho de 2006, não pertencentes à reforma agrária.

No âmbito da América Latina, a agricultura familiar representa mundialmente, segundo a Sociedade Nacional de Agricultura (SNA, 2014), 30\% da produção agrícola no Uruguai, $25 \%$ no Chile, $20 \%$ no Paraguai e 19\% na Argentina. No Brasil, esse segmento é responsável por $38 \%$ do valor Bruto da Produção (MDA, 2006). Dentre os países da América Latina e Caribe, existem cerca de 15 milhões de estabelecimentos familiares, ocupando aproximadamente 400 milhões de hectares. Esses países apontam as seguintes características para o segmento: as propriedades precisam ser geridas pelos membros das famílias e a maior parte da mão de obra também ser familiar (BERDEGUÉ; FUENTEALBA, 2011).

No entanto, no Brasil, os agricultores familiares, muitas vezes, ainda carecem de informações e de assistência técnica para acessarem alguns programas de políticas públicas, que são primordiais para melhorar, aumentar e qualificar ainda mais a sua produção (AUGUSTO; SACHUK, 2008; SOUZA et al., 2011; DE PAULA et al., 2014; BUENO; SILVA, 2014). Outros gargalos também podem ser vivenciados por eles (agricultores familiares), sendo: pouca área de terra, baixa disponibilidade de recursos financeiros, Assistência Técnica e Extensão Rural (ATER) insuficiente, falta de regulamentação dos processos artesanais de produção de alimentos, dificuldades de acesso ao mercado, entre outros, sendo essas questões limitadoras para atingir maior competitividade e gerar o desenvolvimento das propriedades (SOUZA et al., 2011; DE PAULA et al., 2014).

Nesse sentido, com o objetivo de fortalecer o segmento da agricultura familiar no Brasil, foram criados e implantados alguns programas que fazem parte de políticas públicas, tais como o $\mathrm{PRONAF}$, o PAA e o PNAE (PEREIRA; NASCIMENTO, 2014). No entanto ressalta-se que as políticas públicas de custeio agrícola são essenciais para o desenvolvimento, não somente econômico, mas também social, no sentido de fortalecimento dos agricultores familiares.

Sabe-se da grande dificuldade que os agricultores familiares enfrentam para produzir e também escoar sua produção, bem como para ter uma vida de qualidade no meio rural. Nesse sentido, o objetivo do presente estudo foi analisar as principais estratégias utilizadas pelos agricultores familiares tradicionais de Dourados, MS, para a geração de renda.

\section{AGRICULTURA FAMILIAR NO BRASIL}

No universo da agricultura existem dois importantes segmentos produtivos que impactam no Produto Interno Bruto (PIB): a agricultura não familiar e a agricultura familiar. A agricultura familiar recebeu várias definições, sendo caracterizada como agricultura de subsistência, de pequena produção e pobreza 
rural. Somente a partir dos trabalhos de Guanziroli e Cardim (2000), com o Novo Retrato da Agricultura Familiar Redescoberto, que se percebeu o quanto o segmento é importante para o desenvolvimento do país (GUANZIROLI et al., 2011).

A partir dos anos de 1990, esse segmento foi reconhecido pela sua categoria social e produtiva, sendo criadas e implantadas políticas públicas a seu favor. Destaca-se que, até antes desse período, as políticas públicas eram destinadas às médias e às grandes propriedades (ESQUERDO-SOUZA; BERGAMASCO, 2015).

Assim, segundo dos dados do censo agropecuário de 2006, foram identificados 4.367.902 estabelecimentos de agricultores familiares, $84,4 \%$ dos estabelecimentos brasileiros, ocupando uma área de 80,25 milhões de hectares, ou seja, 24,3\% da área ocupada pelos estabelecimentos agropecuários brasileiros e são responsáveis por 38\% do Valor Bruto da Produção (MDA, 2006; PLEIN; FILIPPI, 2011; DE PAULA et al., 2014). Correspondem, economicamente, a $10 \%$ do Produto Interno Bruto (PIB), 38\% do Valor Bruto da Produção Agropecuária (MDA, 2014).

\section{DESENVOLVIMENTO ECONÔMICO, REGIONAL E LOCAL}

O termo desenvolvimento econômico teve surgimento no século XX. Embora não exista uma única definição para o termo, ao longo do tempo duas correntes de economistas tentaram defini-lo. A primeira, mais teórica, destaca o crescimento como sinônimo de desenvolvimento, e a segunda corrente, caracterizada pela realidade empírica, entende que o crescimento é condição indispensável para o desenvolvimento, porém não é condição suficiente (SOUZA, 2012).

O mesmo autor continua destacando que o desenvolvimento econômico é definido pela existência de crescimento econômico contínuo, em ritmo superior ao crescimento demográfico, envolvendo mudanças de estrutura e melhorando os indicadores econômicos, sociais e ambientais. Brue (2006) destaca que o desenvolvimento econômico acontece quando uma nação melhora seu padrão de vida.

Todavia o desenvolvimento econômico não ocorre de maneira igual e ao mesmo tempo em todas as partes, sendo esse um processo bastante irregular. Mas, uma vez iniciado em determinados pontos, possui característica para fortificar áreas/regiões mais dinâmicas e que apresentam maior potencial de crescimento (LIMA; SIMÕES, 2010).

Para Karnopp (2012), desenvolvimento regional é um processo de mudança estrutural localizado, determinado por três principais pilares: progresso da própria região, progresso da comunidade ou sociedade que a habita, e progresso de cada indivíduo pertencente à mencionada sociedade. $\mathrm{O}$ autor ainda destaca a existência de três novos conceitos que exemplificam o desenvolvimento regional atual: o distrito industrial, caracterizado por sistema produtivo local; os ambientes inovadores que fornecem elementos, destacando a tecnologia; e, os clusters, sendo estes uma síntese dos dois anteriores.

Cabe dizer que o desenvolvimento local é baseado nos agentes locais, sendo relacionado a iniciativas inovadoras da coletividade, encadeando as potencialidades locais nas condições dadas pelo contexto. Para que esse processo de desenvolvimento seja duradouro, é preciso elevar as oportunidades sociais e a competitividade da economia local, aumentando a renda (BUARQUE, 1999).

Normalmente, segundo o autor acima, o desenvolvimento local está associado às iniciativas inovadoras e mobilizadoras da coletividade, encadeando as potencialidades locais nas condições dadas pelo ambiente externo. Dessa forma, o desenvolvimento local depende da capacidade dos atores locais de compreenderem a realidade e as mudanças do 
ambiente, ampliarem a capacidade de inovação e responderem, de forma eficiente, aos desafios existentes, com suas capacidades e talentos, em um processo permanente de aprendizagem.

\section{MATERIAL E MÉTODOS}

Este item destaca os procedimentos metodológicos utilizados na construção do artigo. De acordo com Creswell (2010), o método de pesquisa envolve a forma de coletar os dados, de analisá-los e a interpretação desses dados que o pesquisador propõe para seu trabalho.

\subsection{Tipo de Pesquisa}

A natureza metodológica deste trabalho foi pautada em métodos mistos que, segundo Creswell (2010), se referem à junção da abordagem qualitativa e quantitativa. A pesquisa possui um enfoque descritivo, em que, de acordo com o mesmo autor, se relata o comportamento de uma determinada variável da amostra, utilizando instrumentos estatísticos para analisar as variáveis.

\section{2 Área de estudo e amostra}

O estudo foi realizado no município de Dourados, Mato Grosso do Sul, Brasil, contanto com uma amostra de 182 agricultores familiares tradicionais possuidores da Declaração Anual do Produtor Rural (DAP). Para calcular o tamanho da amostra, é necessário usar algum método estatístico. Nesse sentido, foi utilizada a fórmula de amostragem sistemática apresentada por Barbetta (1994), sendo:

$$
\mathrm{n}_{0}=\frac{1}{\left(\mathrm{E}_{0}\right)^{2}} \quad \frac{\mathrm{n}=\mathrm{N} \cdot \mathrm{n}_{0}}{\mathrm{~N}+\mathrm{n}_{0}}
$$

Onde:

$\mathrm{N}=$ tamanho (número de elementos) da população, $\mathrm{n}=$ tamanho (número de elementos) da amostra,

$\mathrm{n}_{0}=$ uma primeira aproximação do tamanho da amostra,

$\mathrm{E}_{0}=$ erro amostral tolerável.

Para realizar o cálculo estatístico, foi considerado um universo de 2.207 agricultores familiares tradicionais (Dados da pesquisa). O valor do erro amostral utilizado para esse cálculo foi de 8,2\%, constituindo uma amostra de 139.

\subsection{Técnicas de pesquisa e análise dos dados}

A pesquisa foi dividida em duas etapas. Na primeira utilizou-se uma entrevista aberta, na qual, segundo Minayo (2008), o entrevistado fala, livremente, sobre a temática proposta pelo entrevistador, e o entrevistador poderá fazer perguntas no decorrer da conversa para alcançar maior profundidade nas respostas. Essa entrevista foi realizada com o Coordenador da Agência Municipal da AGRAER de Dourados, MS, no dia 12 de março de 2015, com o intuito de coletar dados sobre a quantidade de agricultores e de contratos do PRONAF realizados pelos munícipes de Dourados, MS.

Na segunda etapa, utilizou-se um questionário semiestruturado, que foi aplicado pelos servidores da AGRAER a uma amostra populacional de agricultores familiares tradicionais, do município de Dourados, MS (139 famílias). Destaque-se que os selecionados fizeram parte de uma pesquisa referente à Chamada Pública da Sustentabilidade do Ministério do Desenvolvimento Agrário (MDA). As entrevistas foram realizadas antes das intensas chuvas que caíram no município, nos meses de dezembro de 2015 e janeiro de 2016.

Após a realização da entrevista e da aplicação dos questionários, os dados foram tabulados e processados eletronicamente utilizando-se o programa estatístico SPSS (versão 21). Foram 
calculadas estatísticas, as quais foram apresentadas na forma de tabelas e figuras seguidas de sua análise.

\section{RESULTADOS E DISCUSSÃO}

Neste item apresentam-se as características das famílias em análise e de suas respectivas propriedades. A seguir destacam-se a produção e a renda obtida.

\subsection{Produtores familiares e características das propriedades}

Da população residente no município de Dourados, MS, 2.626 são agricultores familiares possuidores da DAP. A Tabela 1 apresenta uma caracterização dos agricultores familiares de Dourados com base nos dados oficiais do Ministério do Desenvolvimento Agrário (MDA).

Tabela 1 - Modalidade e quantidade de agricultores familiares que possuem a DAP, pertencentes ao município de Dourados, MS, 2015

\begin{tabular}{l|c}
\hline \multicolumn{1}{c|}{ Modalidade de produtores familiares } & $\begin{array}{c}\text { Frequência absoluta de } \\
\text { produtores com DAP }\end{array}$ \\
\hline Comunidades Quilombolas & 12 \\
Agrovila (Assentamento realizado pela Prefeitura) & 39 \\
Comunidades Indígenas & 150 \\
Assentamentos $\{$ Lagoa Grande & 151 \\
Agricultores Tradicionais & 67 \\
\hline Total & 2.207 \\
\hline
\end{tabular}

Fonte: Dados do MDA obtidos através da entrevista com o coordenador da AGRAER, em 6 de julho de 2015.

Nota: Como tradicionais consideram-se, neste trabalho, os agricultores familiares que não fazem parte de assentamentos rurais, de comunidades quilombolas ou indígenas.

De acordo com a Tabela 1, o município de Dourados possui 2.626 agricultores familiares que detêm a DAP. Desse total, 2.074 estão ativadas e 552 desativadas. Nesse caso, o número de agricultores com DAP ativa e desativada sofre alteração no decorrer dos dias, pois aqueles produtores que não possuem DAP poderão aderir a qualquer momento, enquadrando-se nos requisitos exigidos pelo órgão, e isso alte- rará o número de agricultores no decorrer do período.

Ao analisar a composição de pessoas residentes nas propriedades, a partir dos questionários aplicados, tem-se uma média de três pessoas por propriedade rural, sendo o mínimo de um morador, e o máximo, de sete moradores. Com relação à escolaridade dos produtores (Tabela 2), os dados referem-se ao titular da DAP. 
Tabela 2 - Grau de escolaridade dos produtores familiares tradicionais, de Dourados, MS, 2015

\begin{tabular}{l|c|c|c}
\hline \multicolumn{1}{c|}{ Grau de escolaridade } & $\begin{array}{c}\text { Frequência } \\
\text { absoluta }\end{array}$ & $\begin{array}{c}\text { Frequência } \\
\text { relativa (\%) }\end{array}$ & $\begin{array}{c}\text { Porcentagem } \\
\text { Acumulada }\end{array}$ \\
\hline Sem resposta & 5 & 2,75 & - \\
Sem escolaridade & 6 & 3,3 & 6,05 \\
Ensino fundamental incompleto & 65 & 35,71 & 41,76 \\
Ensino fundamental completo & 32 & 17,58 & 59,34 \\
Ensino médio incompleto & 21 & 11,54 & 70,88 \\
Ensino médio completo & 36 & 19,78 & 90,66 \\
Superior incompleto & 4 & 2,2 & 92,86 \\
Superior completo & 13 & 7,14 & 100,00 \\
\hline Total & $\mathbf{1 8 2}$ & $\mathbf{1 0 0}$ & \\
\hline
\end{tabular}

Fonte: Dados da pesquisa.

Nota: Destaque-se que os dados referem-se à amostra de 182 famílias pesquisadas.

Com relação ao tamanho, essas propriedades rurais variam de 1 hectare a 100 hectares. O tamanho médio das pro- priedades pesquisadas é de 14,76 hectares (Tabela 3).

Tabela 3 - Tamanho das propriedades rurais dos agricultores familiares tradicionais, de Dourados, MS, 2015

\begin{tabular}{c|c|c|c}
\hline $\begin{array}{c}\text { Tamanho da } \\
\text { propriedade (ha) }\end{array}$ & $\begin{array}{c}\text { Frequência } \\
\text { absoluta }\end{array}$ & $\begin{array}{c}\text { Frequência relativa } \\
\mathbf{( \% )}\end{array}$ & $\begin{array}{c}\text { Porcentagem } \\
\text { Acumulada }\end{array}$ \\
\hline Menos de 1 até 10 & 95 & 52,20 & - \\
Mais de 10 até 20 & 40 & 21,98 & 74,18 \\
Mais de 20 até 30 & 27 & 14,83 & 89,01 \\
Mais de 30 até 40 & 11 & 6,04 & 95,05 \\
Mais de 40 até 50 & 5 & 2,75 & 97,80 \\
Mais de 50 até 60 & 2 & 1,10 & 98,90 \\
Mais de 60 até 70 & - & 0,00 & 98,90 \\
Mais de 70 até 80 & 1 & 0,55 & 99,45 \\
Mais de 80 até 90 & - & 0,00 & 99,45 \\
Mais de 90 até 100 & 1 & 0,55 & 100,00 \\
\hline Total & $\mathbf{1 8 2}$ & $\mathbf{1 0 0}$ & \\
\hline
\end{tabular}

Fonte: Dados da pesquisa.

A Tabela 3 mostra que o maior percentual $(52,20 \%)$ corresponde a propriedades com até 10 hectares, o que representa uma concentração de pessoas com pouco espaço (ha) para produzir. Quando analisadas as propriedades que variam de mais de 10 até 60 hectares, apenas $46,70 \%$ da amostra se enquadram nessa faixa e $1,1 \%$ possuem mais de 60 até 100 hectares.

De acordo com dados da Sangalli (2013), a média de hectares dos agricultores familiares do assentamento Lagoa Grande, localizado no município de Dourados, MS, é de 25,9ha e, com base nos dados do INCRA (2015), a média de hectares dos agricultores pertencentes ao assentamento Amparo, também no município de Dourados-MS, é de 16,8ha. Diante desses dados, diferentes autores destacam que um fator limitador para a produção da agricultura familiar é a pequena área de terra (SOUZA et al., 2011; DE PAULA et al., 2014). 
Destaque-se que o tamanho médio das propriedades pesquisadas é bem baixo (Tabela 3). E não difere muito da média de hectares das propriedades pertencentes aos assentamentos rurais do município de Dourados.

Embora trabalhos destaquem a precariedade das estradas rurais (BUAINAIN; GARCIA, 2013; VILPOUX, 2014), a pesquisa apontou que, para a maioria dos respondentes $(67 \%)$, a estrada até sua propriedade está em boas condições de uso. Como toda a produção de Dourados, MS, é escoada pelas rodovias, ter essa via de transporte em boas condições é indispensável para os produtores rurais, que, na maioria das vezes, moram longe dos centros de distribuição.

\subsection{Produtos cultivados nas propriedades rurais e fonte de renda}

De acordo com Almeida e Kudlavicz (2011), terra é sinônimo de vida e trabalho e, sem dúvida, os agricultores familiares vêm trabalhando arduamente para conquistarem uma vida digna no meio rural. Mediante as culturas por eles cultivadas, buscam diferentes estratégias, como a diversificação, para a geração de renda.

Além da comercialização de seus produtos, muitos agricultores familiares praticam outras atividades fora da propriedade para complementar a renda familiar. A Tabela 4 apresenta as principais atividades desenvolvidas nas propriedades.

Tabela 4 - Principais produtos e culturas desenvolvidas nas propriedades dos agricultores familiares tradicionais, de Dourados, MS, 2015

\begin{tabular}{l|c|c}
\hline \multicolumn{1}{c|}{ Principais produtos e culturas* } & $\begin{array}{c}\text { Frequência absoluta/ } \\
\text { propriedade }\end{array}$ & $\begin{array}{c}\text { Frequência relativa } \\
\mathbf{( \% )}\end{array}$ \\
\hline Milho & 126 & 69,23 \\
Soja & 113 & 62,09 \\
Mandioca & 35 & 19,23 \\
Horta & 30 & 16,48 \\
Leite & 27 & 14,84 \\
Arroz & 9 & 4,95 \\
Olerícolas & 7 & 3,85 \\
Hortifruti & 7 & 3,85 \\
Frutas & 4 & 2,2 \\
Cana-de-açúcar & 2 & 1,1 \\
Não possui culturas agrícolas & 2 & 1,1 \\
Eucalipto & 3 & 1,65 \\
Turismo rural & 1 & 0,55 \\
Feijão & 1 & 0,55 \\
Sorgo & 1 & 0,55 \\
\hline
\end{tabular}

Fonte: Dados da pesquisa.

*O entrevistado pode assinalar mais de uma alternativa.

Verifica-se que, apesar de os agricultores familiares cultivarem uma variedade de produtos, o milho e a soja destacam-se como os cultivos mais importantes. No entanto é importante mencionar que os produtores tanto comercializam como consomem os produtos cultivados na propriedade.
No uso das terras para lavouras, o Censo de 2006 destaca que ocorreu um aumento no percentual de áreas plantadas, principalmente na expansão das culturas cuja principal finalidade é a exportação. Assim, o censo apresenta que houve uma redução na área ocupada com arroz $(65,35)$, com feijão $(25,24)$ e com trigo 
$(17,94)$. Por outro lado, a mandioca, sendo considerado um dos produtos básicos da dieta alimentar, teve um aumento significativo na área colhida, passou de 14.367 hectares colhidos para 26.881 hectares, no período de 1995/96 a 2006 (ALMEIDA; KUDLAVICZ, 2011).

A multifuncionalidade da propriedade é uma questão comum no contexto rural, pois desperta a consciência e reconhece os valores de várias oportunidades da propriedade, tais como, amenidades ambientais, oportunidades de turismo rural, a qualidade dos alimentos, gestão da paisagem, a preservação da biodiversidade, junto com a produção de alimentos e fibras (BARBIERI; VALDIVIA, 2010).

Desse modo, a diversificação da produção, além de ser uma prática fundamental para o equilíbrio ecológico, tão importante aos sistemas agrícolas, também é considerada uma estratégia para a geração contínua de renda pelos agricultores familiares ao longo do ano, considerando a sazonalidade de produção de cada espécie cultivada (GOMES et al., 2014). Através desta pesquisa, percebeu-se uma diversidade de culturas agrícolas e de atividades pecuárias nas proprieda- des, objetivando a geração de emprego e renda para um número considerável de famílias e cooperando assim para o desenvolvimento local.

Mikulcak et al. (2015) destacam que, diante de um ambiente cada vez mais globalizado, as propriedades rurais são confrontadas com enormes desafios para alcançar o desenvolvimento. E faz-se necessário usar vários mecanismos para a geração de renda, como a diversificação da produção.

Com relação à análise das principais atividades pecuárias desenvolvidas nas propriedades pesquisadas, a maioria $(63,74 \%)$ dos entrevistados destacou que não possui animais na propriedade (Tabela 5), cultivando apenas culturas agrícolas.

Com relação aos dados do Censo Agropecuário de 2006, a produtividade do gado bovino, comparado ao ano de 1996, teve um acréscimo de 3,17\%. No entanto, quando comparado ao volume de produção de lavoura temporária, percebe-se que o estado de Mato Grosso do Sul deixou de ser, no período em análise, a terra do boi gordo para ser a terra da soja (ALMEIDA; KUDLAVICZ, 2011).

Tabela 5 - Diversidade animal nas propriedades dos agricultores familiares tradicionais, de Dourados, MS, 2015

\begin{tabular}{l|c|c}
\hline \multicolumn{1}{c|}{ Principais atividades pecuárias* } & $\begin{array}{c}\text { Frequência absoluta } \\
\text { de respondentes }\end{array}$ & $\begin{array}{c}\text { Frequência relativa } \\
\mathbf{( \% )}\end{array}$ \\
\hline Não possui animais & 116 & 63,74 \\
Aves & 62 & 34,07 \\
Bovino & 33 & 18,13 \\
Suíno & 26 & 14,29 \\
Equino & 7 & 3,85 \\
Caprino & 3 & 1,65 \\
Piscicultura & 3 & 1,65 \\
\hline
\end{tabular}

Fonte: Dados da pesquisa.

*O entrevistado pode assinalar mais de uma alternativa.

A partir da análise das Tabelas 4 e 5, fica visível que, nas propriedades pesquisadas, embora haja um percentual expressivo de produtores que cultivam milho e soja, a produção familiar é bastante diversificada. No entanto outro dado apresentado na Tabela 5 revela que mais da metade $(63,74 \%)$ dos pesquisados 
não possui animais em suas propriedades, destacando-se a produção agrícola. As demais famílias, 36,26\% da amostra, combinam cultivos agrícolas e criações. Essa diversificação é primordial para a geração de renda e fixação do homem no meio rural. Grande parte desses produtos, no entanto, não é utilizada somente para a geração de renda, mas, sim, para o autoconsumo, sendo esse item um grande ganho para as famílias, pois, se não pudessem produzir esses alimentos, teriam que adquiri-lo no mercado.

Com relação ao modo de comercialização da produção por parte dos agricultores pesquisados, há uma grande diversidade de formas, conforme consta na Tabela 6. Destacando-se o armazém/ cerealista e a venda direta, com 52,75\% e $25,82 \%$, respectivamente.

Tabela 6 - Canais de comercialização dos produtos dos agricultores familiares tradicionais, de Dourados, MS, 2015

\begin{tabular}{l|c|c}
\hline \multicolumn{1}{c|}{ Canais de comercialização dos produtos* } & Frequência & Percentual (\%) \\
\hline Armazém/Cerealista & 96 & 52,75 \\
Venda direta & 47 & 25,82 \\
PAA & 32 & 17,58 \\
Intermediário & 21 & 11,54 \\
Cooperativa & 13 & 7,14 \\
Laticínio & 8 & 4,4 \\
PNAE & 6 & 3,3 \\
Frigorífico & 5 & 2,75 \\
\hline
\end{tabular}

Fonte: Dados da pesquisa.

*O entrevistado pode assinalar mais de uma alternativa.

A inserção da produção dos agricultores familiares no mercado ainda é um grande desafio enfrentado por eles, sendo que, muitas vezes, carecem de logística adequada para o transporte. Nesse sentido, acabam não tendo forças para comercializar sua produção de forma mais eficiente. Destaca-se o pequeno percentual de agricultores que comercializam sua produção via cooperativas (7,14\%), e esta poderia ser uma excelente alternativa para obterem ganhos.

Embora grande parte dos produtores familiares possua uma diversificação na sua produção, produtos para comercialização e para o consumo, muitos dos agricultores alocam seus recursos em um conjunto de atividades que incluem atividades agrícolas e não agrícolas. Assim, além da renda agrícola e não agrícola advinda da propriedade, os agricultores familiares buscam alternativas para obter renda externa. Com relação à pesquisa, a população entrevistada apresentou elevado percentual de recursos financeiros advindos de fora da propriedade, totalizando $63,19 \%$ dos agricultores (Gráfico 1). 

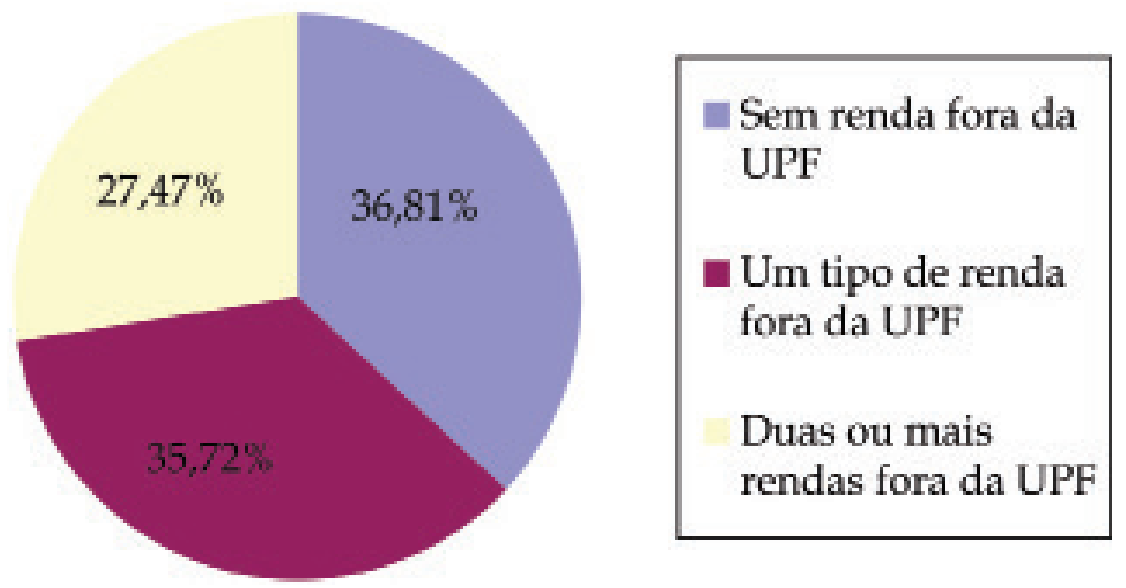

Gráfico 1 - Recurso financeiro obtido pelos agricultores familiares tradicionais de Dourados, MS, com trabalho fora da Unidade de Produção Familiar (UPF)

Fonte: Dados da pesquisa.

Do rendimento obtido pelas famílias fora da propriedade, a média é de $\mathrm{R} \$$ $776,29 /$ mês. No trabalho realizado por Vieira-Filho (2013) com base nos dados do Censo Agropecuário 2006, 90\% de estabelecimentos familiares estão configurados no quadro de extrema pobreza, sendo que a renda para esses produtores está entre zero a dois salários mínimos mensais, tornando-se, assim, indispensável que haja a combinação de outras fontes de renda.

Para complementar a renda da produção, muitos agricultores exercem atividades externas à propriedade, situação em que a renda líquida mensal máxima obtida, pela população pesquisada, alcança o valor mensal de $\mathrm{R} \$ 4.500,00$. Porém $36,81 \%$ dos agricultores não possuem rendimento externo.

A composição do rendimento das famílias pesquisadas ocorre da seguinte forma: $36,81 \%$ possuem somente rendimento a partir das atividades da propriedade e $63,19 \%$ possuem rendimento externo para complementar a renda familiar. Sendo que, $27,47 \%$ dos entrevistados possuem mais de uma fonte de renda externa e $35,72 \%$ possui apenas uma fonte de renda externa (Gráfico 1). Das rendas obtidas de fora da propriedade, os recursos da previdência social se destacam entre os agricultores, com $34,07 \%$, sendo compostos nos rendimentos de aposentadoria/pensão. Esse dado mostra que o meio rural possui uma parcela de população com idade mais avançada (Tabela 7).

Tabela 7 - Atividades desenvolvidas e renda obtida fora da propriedade pelos agricultores familiares tradicionais de Dourados, MS, 2015

\begin{tabular}{l|c|c}
\hline \multicolumn{1}{c|}{ Rendimento fora da propriedade } & $\begin{array}{c}\text { Frequência } \\
\text { absoluta }\end{array}$ & $\begin{array}{c}\text { Frequência } \\
\text { relativa (\%) }\end{array}$ \\
\hline Aposentado & 55 & 30,22 \\
Serviços gerais/diarista & 24 & 13,19 \\
Pensionista & 7 & 3,85 \\
Professor & 5 & 2,75 \\
Artesanato & 4 & 2,2 \\
Motorista & 3 & 1,65 \\
\hline
\end{tabular}

Fonte: Dados da pesquisa. 
Segundo Helfand e Pereira (2012), é cada vez mais visível a necessidade de maior integração entre as atividades agrícolas e não agrícolas. Bem como novas formas de organização do trabalho, para garantir um rendimento maior no meio rural.

Diante do exposto, a renda obtida fora da propriedade já é uma realidade bastante antiga e comum na agricultura familiar. Segundo Shanin (2008), os agricultores familiares, destacando os séculos XXe XXI, passaram a adquirir flexibilidade para encontrar novas formas de ganhar a vida, assim, combinando trabalho no campo e fora dele.

Essa realidade não existe apenas no Brasil. Em torno de 63\% das unidades produtivas na Europa possuem pelo menos um membro familiar que desempenha atividades não agrícolas ou fora do estabelecimento. Com o passar do tempo, o próprio Banco Mundial produziu estudos estimulando a combinação de atividades agrícolas e não agrícolas para a redução da pobreza e melhoria da situação socioeconômica nas áreas rurais (ESCHER et al., 2014).

\section{CONSIDERAÇÕES FINAIS}

Com base nos resultados obtidos a partir da pesquisa realizada, é possível verificar a importância da agricultura familiar tradicional em Dourados-MS para a manutenção das famílias no campo, bem como sua participação na produção de alimentos para a geração de renda e também para o consumo familiar. No entanto nota-se que estes agricultores possuem uma pequena quantidade de terra e, na maioria dos casos, precisam unir atividades agrícolas e não agrícolas para aumentar seus rendimentos financeiros.

Com relação aos canais de comercialização, as cooperativas não foram muito representativas na amostra. Destaque-se que esta poderia ser uma excelente alternativa para a obtenção de ganhos, pois através da união dos agricultores seria possível minimizar alguns gargalos existentes.

A despeito dos ganhos financeiros, fica evidente a importância da diversificação da produção, sendo primordial para a venda e para o consumo da família. Além disso, a renda externa se faz importante, pois representa um complemento para o agricultor familiar, sendo que boa parte provém de rendimentos da Previdência Social.

Por fim, num contexto de desenvolvimento local/regional, é importante dar mais atenção à agricultura familiar, deixar de vê-la como 'agricultura de subsistência' e enxergar nela o seu potencial de inserção produtiva e de mercado. Trata-se de um segmento muito importante para o abastecimento, a produção e a distribuição de alimentos e, como tal, deve ser tratada pelo setor público tanto quanto pelo privado. Destaca-se que mais estudos são necessários para avaliar o papel dos próprios produtores nesse contexto, bem como sua inserção nos canais de comercialização.

\section{Agradecimentos}

À Fundação de Apoio ao Desenvolvimento do Ensino, Ciência e Tecnologia do.

\section{REFERÊNCIAS}

ALMEIDA, Rosemeire Aparecida de; KUDLAVICZ, Mieceslau. A potencialidade da pequena unidade de produção em Mato Grosso do Sul: os censos agropecuários 1995/96 e 2006 em debate. In: FAISTING, A. L.; FARIAS, M de F. L. de (Org.). Direitos humanos, diversidade e movimentos sociais: um diálogo necessário. Dourados, MS: Ed. UFGD, 2011. p. 45-66.

AUGUSTO, Cleiciele Albuquerque; SACHUK, Maria Iolanda. Competitividade da agricultura orgânica no estado do Paraná. Caderno de Administração, v. 15, n. 2, p. 9-18, 2008.

BARBETTA, Pedro Alberto. Estatística aplicada às Ciências Sociais. 1. ed. Florianópolis: UFSC, 1994. 
BARBIERI, Carla; VALDIVIA, Corinne. Recreation and agroforestry: examining new dimensions of multifunctionality in family farms. Journal of Rural Studies, v. 26, n. 4, p. 465-473, 2010.

BERDEGUÉ, Julio A.; FUENTEALBA, Ricardo. Latin America: the state of smallholders in agriculture. In: IFAD CONFERENCE ON NEW DIRECTIONS FOR SMALLHOLDER AGRICULTURE, 2011. p. 25.

BRASIL. Senado Federal. Lei $n^{0}$ 11.326, de 24 de julho de 2006. Estabelece as diretrizes para a formulação da Política Nacional da Agricultura Familiar e Empreendimentos Familiares Rurais. Disponível em: <http:// www.planalto.gov.br/ccivil_03/_ato20042006/2006/lei/111326.htm>. Acesso em: 3 mar. 2014.

BRUE, Stanley L. História do pensamento econômico. Tradução de Luciana Penteado Miquelino. São Paulo: Thomson Learning, 2006.

BUAINAIN, A. M.; GARCIA, J. R. Contextos locais ou regionais: importância para a viabilidade econômica dos pequenos produtores. In: SANTOS, M. de M.; PINHEIRO, B.; SANTANA, C.; GUEDES, A. C.; BARBOSA, M. M. T. L.; SETUBAL, J. H.; PINHEIRO, B.; SANTANA, C. (Org.). A pequena produção rural e as tendências do desenvolvimento agrário brasileiro: ganhar tempo é possível? Brasília: CGEE, 2013.

BUARQUE , Sérgio C. Metodologia de planejamento do desenvolvimento local e municipal sustentável. Material para orientação técnica e treinamento de multiplicadores e técnicos em planejamento local e municipal. Brasília, DF: IICA, 1999.

BUENO, C. da S.; SILVA, P. A. de O. Redes de informação como instrumento ao planejamento do desenvolvimento dos assentamentos rurais: o modelo do programa "PLANEJA" da EMBRAPA. In: CONGRESSO DA SOCIEDADE BRASILEIRA DE ECONOMIA, ADMINISTRAÇÃO E SOCIOLOGIA RURAL. Anais... Goiânia, GO: Sober, 2014.

CRESWELL, John W. Projeto de pesquisa: métodos qualitativo, quantitativo e misto. 3. ed. Porto Alegre, RS: Artmed, 2010. 296 p. Cap. 1.

DE PAULA, Márcia Maria; KAMIMURA, Quésia Postigo; SILVA, José Luis Gomes da. Mercados institucionais na agricultura familiar: dificuldades e desafios. Revista de Política Agrícola, n. 1, p. 33-43, 2014.

ESCHER, Fabiano; SCHNEIDER, Sérgio; SCARTON, Luciana Maria; CONTERATO, Marcelo Antênio. Caracterização da pluriatividade e dos plurirrendimentos da agricultura brasileira a partir do Censo Agropecuário 2006. Revista de Economia e Sociologia Rural, v. 52, n. 4, p. 643-668, 2014.

ESQUERDO-SOUZA, Vanilde Ferreira de; BERGAMASCO, Sonia M. Pessoa Pereira. Políticas públicas para a agricultura familiar brasileira: um estudo sobre o PRONAF nos municípios do circuito das frutas - SP. Revista Extensão Rural, Santa Maria, RS, v. 22, n. 1, jan./mar. 2015.

FAO/INCRA. Projeto de cooperação técnica INCRA/FAO. Novo retrato da agricultura familiar. O Brasil redescoberto. Brasília, 2000.

GOMES, Juliana Benites Padua; BEZERRA, Gleicy Jardi; NASCIMENTO, Jaqueline Silva; SCHLINDWEIN, Madalena Maria; PADOVAN, Milton Parron. Produção orgânica no Assentamento Itamarati, em Ponta Porã, estado de Mato Grosso do Sul, Brasil. Cadernos de Agroecologia, v. 9, n. 4, 2014.

GUANZIROLI, Carlos Enrique; CARDIM, Silvia Elizabeth C. S. Novo retrato da agricultura familiar: o Brasil redescoberto. Brasília: Ministério do Desenvolvimento Agrário, INCRA, Instituto Nacional de Colonização e Reforma Agrária, 2000.

GUANZIROLI, C. E.; DI SABBATO, Alberto; VIDAL, M. de F. Agricultura familiar no Nordeste: uma análise comparativa entre dois censos agropecuários. Fortaleza: Banco do Nordeste do Brasil, 2011.

HELFAND, S.; PEREIRA, V. Determinantes da pobreza rural e implicações para as políticas públicas no Brasil. In: BUAINAIN, A.M. et al. A nova cara da pobreza rural: desafios para as políticas públicas. Brasília: IICA, 2012. (Série Desenvolvimento Rural Sustentável, v. 16, Cap. 4).

INSTITUTO NACIONAL DE COLONIZAÇÃO E REFORMA AGRÁRIA (INCRA). Projetos de reforma agrária conforme fases de implementação. 2015. Disponível em: <http:// 
www.incra.gov.br/sites/default/files/ uploads/reforma-agraria/questao-agraria/ reforma-agraria/projetos_criados-geral.pdf $>$. Acesso em: 12 fev. 2016.

KARNOPP, Érica. Tendências de desenvolvimento da agricultura familiar: uma análise regional. RDE-Revista de Desenvolvimento Econômico, v. 14, n. 26, 2012.

LIMA, Ana Carolina da Cruz; SIMÕES, Rodrigo Ferreira. Teorias clássicas do desenvolvimento regional e suas implicações de política econômica: o caso do Brasil. Revista de Desenvolvimento Econômico, v. 12, n. 21, 2010.

MIKULCAK, Friederike; HAIDER, Jamila L.; ABSON, David J.; NEWIG, Jens; FISCHER, Joem. Applying a capitals approach to understand rural development traps: A case study from post-socialist Romania. Land Use Policy, v. 43, p. 248-258, 2015.

MINAYO, Maria Cecília de Souza. O desafio do conhecimento. 11. ed. São Paulo: Hucitec, 2008.

MINISTÉRIO DO DESENVOLVIMENTO AGRÁRIO (MDA). Agricultura familiar no Brasil e o censo agropecuário 2006. Disponível em: <http://sistemas.mda.gov.br/ arquivos/2246122356.pdf>. Acesso em: 8 mar. 2014.

. A agricultura familiar encerra $2013 \mathrm{com}$ recordes e define novas metas no ano internacional do setor. 2014. Disponível em: <http:/ / portal. mda.gov.br/portal/saf/noticias/item?item_ id=15658991>. Acesso em: 13 abr. 2014.

PEREIRA, Eder Lucinda; NASCIMENTO, Jean Santos. Efeitos do Pronaf sobre a produção agrícola familiar dos municípios tocantinenses. Revista de Economia e Sociologia Rural, Piracicaba, SP, v. 52, n. 01, p. 139-156, jan./mar 2014.

PLEIN, Clério; FILIPPI, Eduardo Ernesto. Capitalismo, agricultura familiar e mercados.
Revista Desenvolvimento Regional, v. 16, n. 3, p. 98-121, 2011.

SANGALLI, A. R. Assentamento Lagoa Grande, em Dourados, MS: aspectos socioeconômicos, limitações e potencialidades para o seu desenvolvimento. 2013. 107 p. Dissertação (Mestrado em Agronegócios) - Universidade Federal da Grande Dourados, Dourados, MS, 2013.

SHANIN, Teodor. Lições camponesas. In: PAULINO, E. T.; FABRINI, J. E. (Org.). Campesinato e territórios em disputa. 1. ed. São Paulo: Expressão Popular/UNESP, 2008. p. 23- 47.

SOCIEDADE NACIONAL DA AGRICULTURA (SNA). Mundo volta suas atenções para a agricultura familiar. 2014. Disponível em: <http://sna.agr.br/mundo-volta-suas-aten coes-para-a-agricultura-familiar/ $>$. Acesso em: 13 abr. 2015.

SOUZA, Paulo Marcelo; FORNAZIER, Armando; PONCIANO, Niraldo José; NEY, Marlon Gomes. Agricultura familiar versus agricultura não-familiar: uma análise das diferenças nos financiamentos concedidos no período de 1999 a 2009. Documentos TécnicoCientíficos, v. 42, n. 1, jan./mar. 2011.

SOUZA, Nali de Jesus de. Desenvolvimento econômico. 6. ed. São Paulo: Atlas, 2012.

VIEIRA-FILHO, José Eustáquio Ribeiro. Distribuição produtiva e tecnológica dos estabelecimentos agropecuários de menor porte e gestão familiar no Brasil. In: CAMPOS, S. K.; NAVARRO, Z. (Org.). A pequena produção rural e as tendências do desenvolvimento agrário brasileiro: ganhar tempo é possível? Brasília, DF: CGEE, 2013. p. 177-199.

VILPOUX, Olivier F. Agrarian reform and cooperation between settlers in the Midwest of Brazil: An institutional approach. Land Use Policy, v. 39, p. 65-77, 2014.

\section{Sobre as autoras:}

Gleicy Jardi Bezerra: Graduada em Administração e mestre em Agronegócios pela Universidade Federal da Grande Dourados (UFGD) e Doutoranda em Agronegócios pela Universidade Federal do Rio Grande do Sul (UFRGS). E-mail: gjardibezerra@gmail.com

Madalena Maria Schlindwein: Doutora em Economia Aplicada pela Esalq/USP. Professora e Pesquisadora da Universidade Federal da Grande Dourados (UFGD). E-mail: MadalenaSchlindwein@ufgd.edu.br 
